ARTICLE

DOI: $10.1038 / s 41467-018-05757-6$

\title{
Interfacing with silica boosts the catalysis of copper
}

\author{
Chaofa Xu (1) ', Guangxu Chen', Yun Zhao', Pengxin Liu1, Xinping Duan (1) 1, Lin Gu (1) 2, \\ Gang Fu', Youzhu Yuan (i) ${ }^{1} \&$ Nanfeng Zheng (iD ${ }^{1}$
}

Metal-support interaction is one of the most important parameters in controlling the catalysis of supported metal catalysts. Silica, a widely used oxide support, has been rarely reported as an effective support to create active metal-support interfaces for promoting catalysis. In this work, by coating $\mathrm{Cu}$ microparticles with mesoporous $\mathrm{SiO}_{2}$, we discover that $\mathrm{Cu} / \mathrm{SiO}_{2}$ interface creates an exceptional effect to promote catalytic hydrogenation of esters. Both computational and experimental studies reveal that $\mathrm{Cu}-\mathrm{H}^{\delta-}$ and $\mathrm{SiO}-\mathrm{H}^{\delta+}$ species would be formed at the $\mathrm{Cu}-\mathrm{O}-\mathrm{SiO}_{x}$ interface upon $\mathrm{H}_{2}$ dissociation, thus promoting the ester hydrogenation by stablizing the transition states. Based on the proposed catalytic mechanism, encapsulting copper phyllosilicate nanotubes with mesoporous silica followed by hydrogen reduction is developed as an effective method to create a practical Cu nanocatalyst with abundant $\mathrm{Cu}-\mathrm{O}-\mathrm{SiO}_{x}$ interfaces. The catalyst exhibits the best performance in the hydrogenation of dimethyl oxalate to ethylene glycol among all reported Cu catalysts.

\footnotetext{
${ }^{1}$ State Key Laboratory for Physical Chemistry of Solid Surfaces, Collaborative Innovation Center of Chemistry for Energy Materials, National \& Local Joint Engineering Research Center for Preparation Technology of Nanomaterials, and National Engineering Laboratory for Green Chemical Productions of Alcohols-Ethers-Esters, College of Chemistry and Chemical Engineering, Xiamen University, Xiamen 361005, China. ${ }^{2}$ Institute of Physics, Chinese Academy of Sciences, Beijing 100190, China. These authors contributed equally: Chaofa Xu, Guangxu Chen. Correspondence and requests for materials should be addressed to G.F. (email: gfu@xmu.edu.cn) or to Y.Y. (email: yzyuan@xmu.edu.cn) or to N.Z. (email: nfzheng@xmu.edu.cn)
} 
eterogeneous catalysis is of vital importance in many fields of chemical, food, energy, and environmental applications. The rational design and fabrication of sufficient active interfaces between metal and (hydr)oxide to facilitate the reactions with multiple reagents has emerged as an effective strategy to prepare heterogeneous catalysts with improved performances. For instance, both $\mathrm{Pt} / \mathrm{FeO}_{x}$ and $\mathrm{Pt} / \mathrm{Fe}$ $(\mathrm{OH})_{x}$ interfaces exhibit excellent performance in $\mathrm{CO}$ oxidation and $\mathrm{CO}$ preferential oxidation $(\mathrm{PROX})^{1-4} \cdot \mathrm{Au} / \mathrm{CeO}_{x}$ and $\mathrm{Au} /$ $\mathrm{TiO}_{x}$ interfaces have been demonstrated to improve the activity of water-gas shift reaction ${ }^{5-7} . \mathrm{Pt} / \mathrm{M}(\mathrm{OH})_{2}(\mathrm{M}=$ metal $)$ interfaces enhance the performance of hydrogen evolution reaction and hydrogen oxidation reaction ${ }^{8-11}$. Such interfacial effects from the strong metal-metal (hydr)oxide interactions were typically observed only when reducible metal oxides (e.g., $\mathrm{TiO}_{x}, \mathrm{CeO}_{x}$, $\mathrm{FeO}_{x}$ ) were used as supports ${ }^{12-17}$. In contrast, $\mathrm{SiO}_{2}$ without reducible metal cations usually serves as 'inert' support, or plays as shell material to fabricate yolk-shell and core-shell metal nanocatalysts to prevent the sintering of metal components ${ }^{18-24}$. Reports on the promotional effects of $\mathrm{SiO}_{2}$ on heterogeneous catalysis are $\operatorname{rare}^{25,26}$.

Here we demonstrate that $\mathrm{SiO}_{2}$ readily creates highly active interfaces with $\mathrm{Cu}$ in the gas-phase hydrogenation of dimethyl oxalate (DMO) into ethylene glycol (EG). In this work, the $\mathrm{Cu}$ $\mathrm{SiO}_{2}$ interfaces were first designed and fabricated by depositing a mesoporous $\mathrm{SiO}_{2}\left(\mathrm{~m}-\mathrm{SiO}_{2}\right)$ layer onto the surface of commercial $\mathrm{Cu}$ powders. With the created $\mathrm{Cu}-\mathrm{SiO}_{2}$ interfaces, the coated $\mathrm{Cu}$ powders exhibited a two-order-of-magnitude enhancement in the activity as compared to the uncoated $\mathrm{Cu}$ powders. Combining experiments with density functional theory (DFT) calculations, we demonstrate that $\mathrm{H}_{2}$ could be activated at the $\mathrm{Cu}^{\delta+}-\mathrm{O}-\mathrm{SiO}_{x}$ interface region, giving rise to $\mathrm{Cu}-\mathrm{H}$ and interfacial $\mathrm{SiO}-\mathrm{H}$ species, which are able to promote the hydrogenation of polar $\mathrm{C}=\mathrm{O}$ bonds. Based on this understanding, a smart strategy by in situ reducing silica coated copper phyllosilicate nanotubes was developed to produce a sophisticated $\mathrm{Cu}-\mathrm{SiO}_{2}$ nanocatalyst with abundant $\mathrm{Cu}-\mathrm{O}-\mathrm{SiO}_{x}$ interface. Such a catalyst exhibited the best reported performance in selective hydrogenation of DMO to EG.

\section{Results and Discussion}

$\mathrm{Cu}-\mathrm{O}-\mathrm{SiO}_{x}$ interfaces boost the catalysis of copper. To create $\mathrm{Cu}-\mathrm{O}-\mathrm{SiO}_{x}$ interfaces, a non-continuous layer of $\mathrm{m}-\mathrm{SiO}_{2}$ was deposited onto the surface of commercial $\mathrm{Cu}$ microparticles (MPs) with diameter of 2-3 $\mu \mathrm{m}$ by hydrolysis of tetraethoxysilane (TEOS) in the presence of cetyltrimethylammonium bromide (CTAB) (See 'Methods' section). Scanning electron microscopy (SEM) and energy dispersive spectroscopy (EDS) analysis (Fig. 1a-h, Supplementary Fig. 1) revealed the successful deposition of a downy layer of $\mathrm{SiO}_{2}$ on $\mathrm{Cu}$ MPs. The mesoporous nature of the $\mathrm{SiO}_{2}$ layer deposited on $\mathrm{Cu}$ MPs was confirmed by the $\mathrm{N}_{2}$ adsorption and desorption isotherm at $77 \mathrm{~K}$ (Supplementary Fig. 2). It should also be noted that the $\mathrm{m}-\mathrm{SiO}_{2}$ layer was not continuously grown on $\mathrm{Cu}$, resulting in the exposure of partial $\mathrm{Cu}$ sites on the as-obtained hybrid of $\mathrm{Cu}-\mathrm{MP} @ \mathrm{~m}-\mathrm{SiO}_{2}$.

To evaluate the $\mathrm{Cu}-\mathrm{O}-\mathrm{SiO}_{x}$ interfacial effect, we chose the gasphase hydrogenation of DMO. ${ }^{27-29}$ As shown in Fig. 1i, Cu MPs without $\mathrm{SiO}_{2}$ coating displayed a negligible activity in the hydrogenation of DMO at the temperature below $250^{\circ} \mathrm{C}$. In comparison, $\mathrm{Cu}$ MPs coated with $\mathrm{m}-\mathrm{SiO}_{2}$ exhibited a significant activity even at the temperature of $210^{\circ} \mathrm{C}$. The turnover rate of carbonyl groups ( $k_{\text {carbonyl group }}$ ) over $\mathrm{Cu}-\mathrm{MP} @ \mathrm{~m}-\mathrm{SiO}_{2}$ was approximately 80 times higher than that on uncoated $\mathrm{Cu}$ MPs at the temperature between 200 and $240{ }^{\circ} \mathrm{C}$. In this comparison, the $k_{\text {carbonyl group }}$ was calculated based on the hydrogenation rate of carbonyl groups over the total amount of $\mathrm{Cu}$ in the catalysts.
The hydrogenation activity of the $\mathrm{Cu}-\mathrm{MP} @ \mathrm{~m}-\mathrm{SiO}_{2}$ catalyst was increased with the temperature. Considering that less $\mathrm{Cu}$ sites were exposed on $\mathrm{Cu}-\mathrm{MP} @ \mathrm{~m}-\mathrm{SiO}_{2}$, the catalytic enhancement induced by the $\mathrm{Cu}-\mathrm{O}-\mathrm{SiO}_{x}$ interfaces was tremendous. Moreover, the apparent activation energy $\left(E_{\mathrm{a}}\right)$ over $\mathrm{Cu}-\mathrm{MP} @ \mathrm{~m}-\mathrm{SiO}_{2}$ was measured to be $107.1 \mathrm{~kJ} \mathrm{~mol}^{-1}$ (Fig. 1j), almost only half of that on $\mathrm{Cu}$ MPs $\left(188.9 \mathrm{~kJ} \mathrm{~mol}^{-1}\right)$, indicating the as-built $\mathrm{Cu}-\mathrm{O}-\mathrm{SiO}_{x}$ interfaces would completely alter the hydrogenation mechanism.

Hydrogenation mechanism over the $\mathrm{Cu}-\mathrm{O}-\mathrm{SiO}_{x}$ interface. The promotional effect of the $\mathrm{Cu}-\mathrm{O}-\mathrm{SiO}_{x}$ interface on the catalytic hydrogenation of DMO was studied by using DFT calculations. In this work, structural models of periodic $\mathrm{Cu}(111)$ with/without $\mathrm{SiO}_{2}$ coating were built to simulate the modified and unmodified $\mathrm{Cu}$ MPs, respectively. Until now, it is still a great challenge to identify the interfacial structure between metal and silica since the $\mathrm{SiO}_{2}$ deposition could present as various crystalline or vitreous films. To simplify the interface model, we assumed that the $\left[\mathrm{SiO}_{4}\right]$ tetrahedra could be stacked on $\mathrm{Cu}(111)$ in a two-dimensional ordered network with a composition of $\mathrm{SiO}_{2.5}$, in which every $\mathrm{Si}$ has one $\mathrm{Si}-\mathrm{O}-\mathrm{Cu}$ bond and three $\mathrm{Si}-\mathrm{O}-\mathrm{Si}$ bonds (Supplementary Fig. 3). According to our DFT calculations, the proposed model was calculated to be exothermic by $0.66 \mathrm{eV} / \mathrm{Si}$ with respective to $\mathrm{Cu}(111)$, a-quartz $\mathrm{SiO}_{2}$ and gaseous $\mathrm{O}_{2}$. Bader charge analysis showed that surface $\mathrm{Cu}$ atoms, which were directly bonded with $\mathrm{O}-\mathrm{SiO}_{3}$, would carry significantly positive charge, implying that the $\mathrm{SiO}_{2}$ overgrowth would lead to the formation of $\mathrm{Cu}^{\delta+}$ species (Supplementary Fig. 3). Interestingly, similar silica films with $\mathrm{c}(2 \times 2)$ structures have been demonstrated to form on $\mathrm{Mo}(112)$ and $\mathrm{Ru}(0001)$ single crystal surfaces ${ }^{30-32}$. As suggested previously, the adsorption energy of oxygen atoms plays an important role in determining whether silica monolayer film can be stabilized on the metal surface or not. In our case, the dissociative adsorption energy of $\mathrm{O}_{2}$ on $\mathrm{Cu}(111)$ was calculated as $-3.13 \mathrm{eV}$, just between those of $\mathrm{Mo}(112)(-5.64 \mathrm{eV})$ and $\mathrm{Ru}(0001)(-2.28$ $\mathrm{eV})$. In addition, $\mathrm{Cu}(111)$ has lattice constant of $2.556 \AA$, matching well with the silica film with a $5.2 \sim 5.3 \AA$ periodicity in the $(2 \times 2)$ manner. All these results indicated that the formation of monolayer $\mathrm{SiO}_{2}$ network over $\mathrm{Cu}(111)$ surfaces is reasonable. On the surface of $\mathrm{Cu}-\mathrm{MP} @ \mathrm{~m}-\mathrm{SiO}_{2}$, there were still a large amount of uncovered $\mathrm{Cu}$ atoms so that the silica film should not be continuous. To account for the experimental observation, we extended our model to a $(8 \times 4)$ structure in which $50 \%\left[\mathrm{SiO}_{4}\right]$ tetrahedra were removed, and the as-generated $\mathrm{Si}-\mathrm{O}$ dangling bonds were saturated by $\mathrm{H}$ atoms. Thus, the $\mathrm{Cu}-\mathrm{O}-\mathrm{SiO}_{x}$ interface turned to be accessible for the substrate molecules. Hereafter, such a model is denoted as $\mathrm{SiO}_{2} / \mathrm{Cu}(111)$.

Hydrogenation on the heterogeneous catalysts usually follows Horiuti Polanyi mechanism, which consists of following steps: (i) dissociation of hydrogen; (ii) adsorption of unsaturated compounds; (iii) stepwise hydrogenation with $\mathrm{H}$ atoms. Supplementary Fig. 4 showed the dissociation of $\mathrm{H}_{2}$ on the two distinct surfaces, i.e., $\mathrm{Cu}(111)$ and $\mathrm{SiO}_{2} / \mathrm{Cu}(111)$. On $\mathrm{Cu}(111), \mathrm{H}-\mathrm{H}$ bond splitting occurred via a homolytic mechanism, generating two hydrogen atoms adsorbed on the three-fold sites. Alternatively, the presence of $\mathrm{Cu}-\mathrm{O}-\mathrm{SiO}_{x}$ interface on $\mathrm{SiO}_{2} / \mathrm{Cu}(111)$ enable $\mathrm{H}_{2}$ activation in a heterolytic way, yielding $\mathrm{Cu}-\mathrm{H}$ and interfacial $\mathrm{SiO}-\mathrm{H}$ species simultaneously at the interface. From $\mathrm{Cu}(111)$ to $\mathrm{SiO}_{2} / \mathrm{Cu}(111)$, the calculated barrier for $\mathrm{H}_{2}$ dissociation does not change too much $(0.28 \mathrm{eV}$ vs. $0.30 \mathrm{eV})$, indicating that heterolytic dissociation could be competitive with the hemolytic one. However, from the viewpoint of thermodynamics, $\mathrm{H}_{2}$ dissociation on $\mathrm{SiO}_{2} / \mathrm{Cu}(111)$ was found to be more exothermic than that on $\mathrm{Cu}(111)(-0.81 \mathrm{eV}$ vs. $-0.47 \mathrm{eV})$ because the interfacial $\mathrm{SiO}-\mathrm{H}$ bond is stronger than $\mathrm{Cu}-\mathrm{H}$ bond. Therefore, even the $\mathrm{H}_{2}$ 

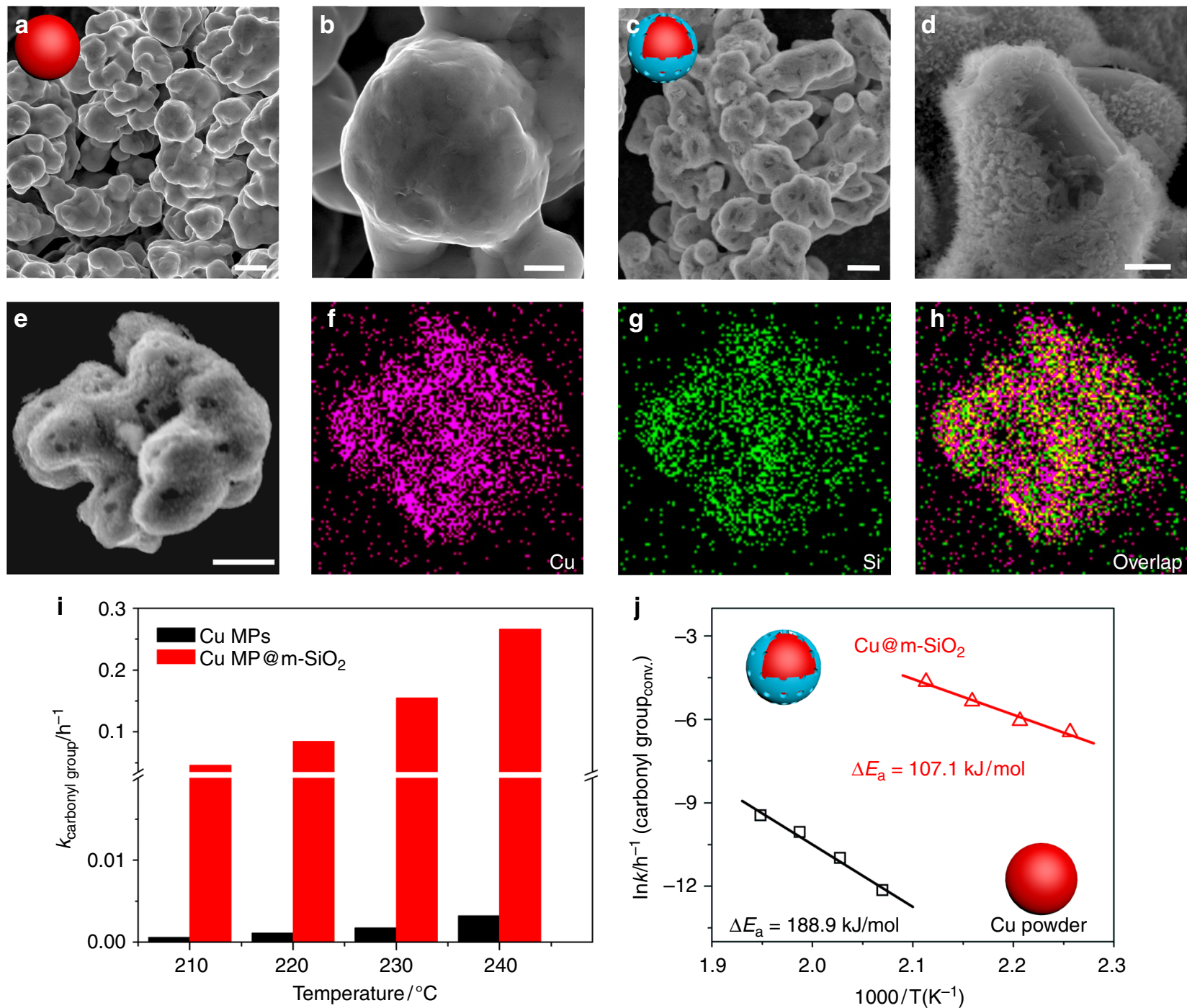

Fig. 1 Demonstration of $\mathrm{Cu}-\mathrm{O}-\mathrm{SiO}_{X}$ interface effect in $\mathrm{DMO}$ hydrogenation. a-d SEM images of $\mathrm{Cu}$ microparticle before (a, b) and after (c, d) coating mesoporous silica; $\mathbf{e}-\mathbf{h}$ EDX mapping images of mesoporous silica coated $\mathrm{Cu}$ microparticles $\left(\mathrm{Cu} @ m-\mathrm{SiO}_{2}\right) ; \mathbf{i}$, $\mathbf{j}$ Catalytic performance and the apparent activation energy $\left(E_{\mathrm{a}}\right)$ of $\mathrm{Cu}$ microparticles before and after coating mesoporous silica for the selective hydrogenation of DMO, respectively; Reaction conditions were as follows: $\mathrm{H}_{2} / \mathrm{DMO}=80 \mathrm{~mol} / \mathrm{mol}, P\left(\mathrm{H}_{2}\right)=3.0 \mathrm{MPa}$. Scale bars in $\mathbf{a}, \mathbf{c}$ and e are $2 \mu \mathrm{m}$. Scale bars in $\mathbf{b}$ and $\mathbf{d}$ are $500 \mathrm{~nm}$

dissociation occurred via the hemolytic route, interfacial $\mathrm{SiO}-\mathrm{H}^{\delta}$ + species would be generated through thermodynamics-driven hydrogen spillover. All these indicated that there existed abundant interfacial $\mathrm{SiO}-\mathrm{H}^{\delta+}$ and $\mathrm{Cu}-\mathrm{H}^{\delta-}$ at the $\mathrm{Cu}-\mathrm{O}-\mathrm{SiO}_{x}$ interfaces upon hydrogenation.

The DMO hydrogenation pathways on $\mathrm{Cu}(111)$ and $\mathrm{SiO}_{2} / \mathrm{Cu}$ (111) were compared, with the optimized structures of transition states (TS') and important intermediates (IMs) illustrated in Fig. 2a, Supplementary Figs. 5 and 6. For clarity, only the lowest energy pathways were shown for these two surfaces. According to our DFT calculations, DMO was weakly adsorbed on both $\mathrm{Cu}$ (111) and $\mathrm{SiO}_{2} / \mathrm{Cu}(111)$ (from i to ii in Fig. 2a). In this regard, there are two possible mechanisms, namely hydroxyl mechanism and alkoxy mechanism. In the former case, the first hydrogen atom would attack the $\mathrm{O}$ end of $\mathrm{C}=\mathrm{O}$ group, producing the hydroxyl intermediate, while in the latter case, $\mathrm{C}$ end of $\mathrm{C}=\mathrm{O}$ group would be hydrogenated first, leading to the formation of alkoxy intermediate. It has been reported previously that hydroxyl intermediate was thermodynamically less favorable than alkoxy intermediate ${ }^{33,34}$. On both surfaces, the hydrogenation of DMO begins with the nucleophilic attack of $\mathrm{H}^{\delta-}$ to the electron deficient carbon of ester group. On $\mathrm{Cu}(111)$, a $1.22 \mathrm{eV}$ barrier (TS1) has to be surmounted when the initial hydrogenation takes place. In contrast, a relative low barrier of $0.77 \mathrm{eV}$ (TS1) is required when the reaction occur at the $\mathrm{Cu}-\mathrm{O}-\mathrm{SiO}_{x}$ interface. It should be noted that both of the reactions proceed with similar endothermicity of $\sim 0.10 \mathrm{eV}$, indicating that the difference in the barrier should be attributed to the electronic effect (from ii to iii in Fig. 2a). Based on the Bader charge analysis, it was found that when $\mathrm{H}^{\delta-}$ approaches, the adsorbed DMO would bear a $\sim-0.5$ a.u. charge. Such a negatively charged TS can be stabilized by the $\mathrm{SiO}-\mathrm{H}^{\delta+}$ species, but repulsive with the co-adsorbed $\mathrm{Cu}-\mathrm{H}^{\delta-}$. This finding nicely explained why the addition of 'inert' silica could significantly enhance the hydrogenation.

Next, the half-hydrogenated intermediate undergoes the second $\mathrm{H}$ addition to give alcohol species (iv in Fig. 2a IM2). On $\mathrm{Cu}(111)$, the TS2 occurs through a reductive elimination of $\mathrm{CH}_{3} \mathrm{O}(\mathrm{O}=) \mathrm{C}-\mathrm{CH}\left(\mathrm{OCH}_{3}\right) \mathrm{O}^{\delta-}$ and $\mathrm{H}^{\delta-}$, yielding a barrier of $1.07 \mathrm{eV}$. Such a high barrier might be originated from the electrostatic repulsion between two negatively charged species. On the contrary, $\mathrm{SiO}-\mathrm{H}^{\delta+}$ at the $\mathrm{Cu}-\mathrm{O}-\mathrm{SiO}_{x}$ interface can 

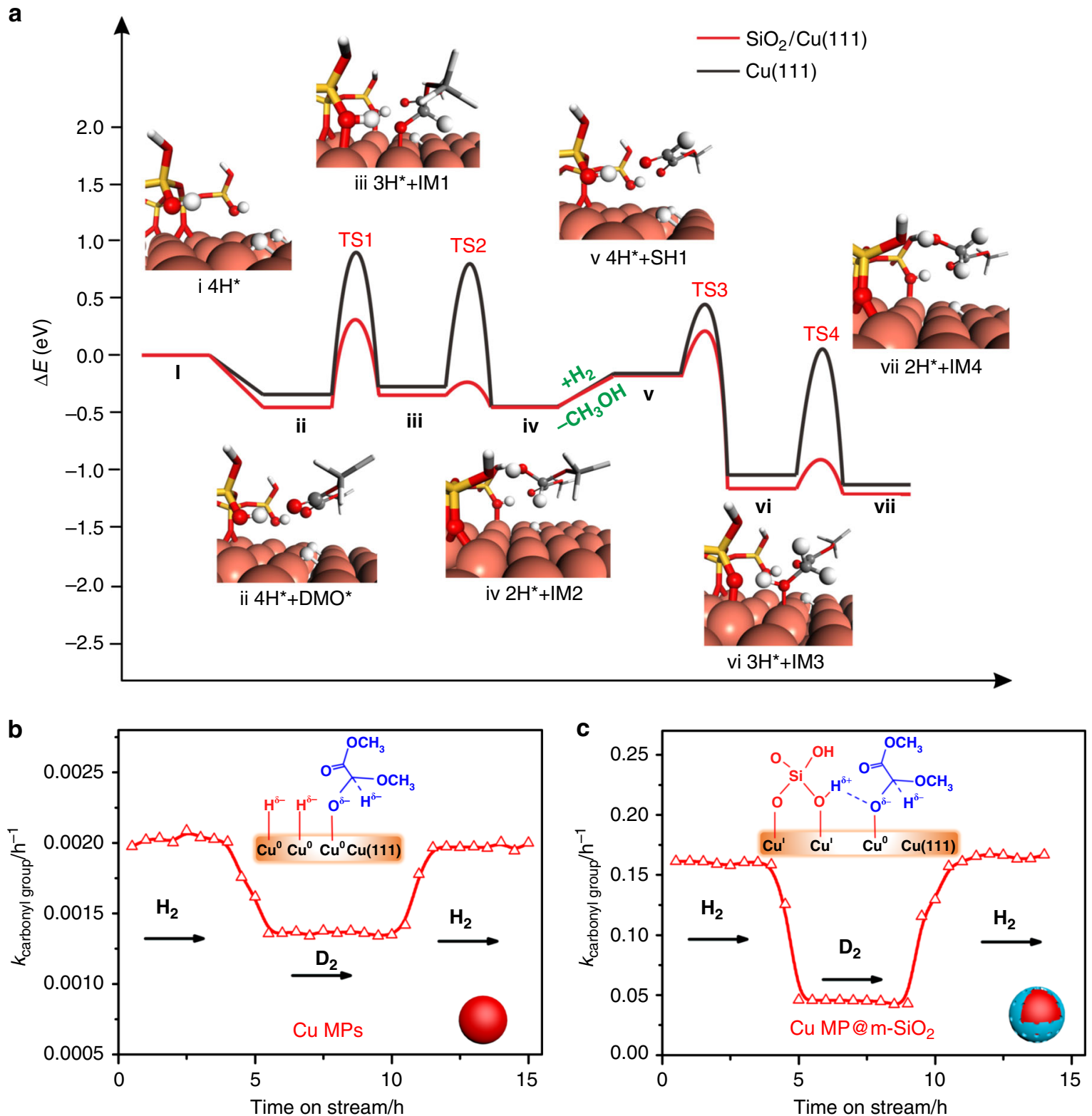

Fig. 2 Mechanism of DMO hydrogenation on $\mathrm{Cu}-\mathrm{O}-\mathrm{SiO}_{x}$ interface. a The DMO hydrogenation pathway on $\mathrm{Cu}(111)$ and $\mathrm{SiO} / \mathrm{Cu}(111) ; \mathbf{b}, \mathbf{c}$ The kinetic isotope effect of $\mathrm{Cu}$ MPs catalyst and Cu MPs@m-SiO ${ }_{2}$ catalyst in hydrogenation of DMO. Reaction conditions were as follows: $\mathrm{H}_{2} / \mathrm{DMO}=80 \mathrm{~mol} / \mathrm{mol}$, $P\left(\mathrm{H}_{2}\right)=3.0 \mathrm{MPa}, T=230^{\circ} \mathrm{C}$

provide a proton, which is quickly transferred to $\mathrm{CH}_{3} \mathrm{O}(\mathrm{O}=)$ $\mathrm{C}-\mathrm{CH}\left(\mathrm{OCH}_{3}\right) \mathrm{O}^{\delta-}$ to make a $\mathrm{O}-\mathrm{H}$ bond by passing a small barrier of $0.11 \mathrm{eV}$ (from iii to iv in Fig. 2a). From this result, the interfacial $\mathrm{SiO}-\mathrm{H}^{\delta+}$ species should be very acidic since the $\mathrm{Cu}$ atoms at the interface can stabilize their deprotonated forms. The proposed mechanism nicely explains why the $\mathrm{Cu}-\mathrm{O}-\mathrm{SiO}_{x}$ interface is a good choice for the hydrogenation reaction. On one hand, the $\mathrm{Cu}-\mathrm{OSi}$ bond is not so strong to inhibit the dissociation of $\mathrm{H}_{2}$. On the other hand, moderate $\mathrm{Cu}-\mathrm{OSi}$ bond would render interfacial $\mathrm{SiO}-\mathrm{H}$ bond suitable strength, which not only stabilizes the charged TS' but also releases a proton when necessary.

For IM2, the co-presence of $\mathrm{OH}$ and OMe groups on the same carbon atoms makes them unstable, which can be easily converted into adsorbed $\mathrm{CH}_{3} \mathrm{O}(\mathrm{O}=) \mathrm{C}-\mathrm{CHO}$ (SH1) plus a methanol molecule (from iv to $\mathrm{v}$ in Fig. 2a). Subsequently, SH1 would undergo step-wise hydrogenation again, passing through
TS3 and TS4, leading to formation of MG species (IM4). Again, the calculated barriers for TS3 and TS4 on $\mathrm{SiO}_{2} / \mathrm{Cu}(111)$ were much lower than those on $\mathrm{Cu}(111)$, and the hydrogenation of aldehyde groups was easier than that of the ester groups (from $\mathrm{v}$ to vii in Fig. 2a). Similarly, MG can further be hydrogenated into EG by consecutive $\mathrm{H}$ atoms addition. DFT calculations show that the hydrogenation of $\mathrm{MG}$ is harder to be conquered than that of DMO. Either on $\mathrm{SiO}_{2} / \mathrm{Cu}(111)$ or $\mathrm{Cu}(111)$, the energy gaps between TS5 and TS1 are nearly the same $(0.42 \mathrm{eV} \sim 0.45 \mathrm{eV})$ (from viii to ix in Supplementary Fig. 5). Structurally, DMO has two ester groups. When one of them is hydrogenated, the other serves as an electron-withdrawing group which can stabilize charged TS' through electron delocalization. Unfortunately, the $\mathrm{CH}_{2} \mathrm{OH}$ group in $\mathrm{MG}$ lacks the ability to delocalize the negative charge upon ester hydrogenation. Thus, the rate determining step for the hydrogenation of DMO to EG is corresponding to the hydrogenation of MG. 
The mechanism suggested by DFT calculations was verified by serial isotope-labeling experiments (Fig. 2b). The kinetic isotope effect (KIE) of Cu MPs@m-SiO ${ }_{2}$ catalyst $\left(k_{\mathrm{H}} / k_{\mathrm{D}}=3.5\right)$ is about two times higher than that of $\mathrm{Cu}$ MPs catalyst $\left(k_{\mathrm{H}} / k_{\mathrm{D}}=1.5\right)$, indicating the different hydrogenation mechanisms on the two catalysts. As shown in Supplementary Fig. 5, not only the $\mathrm{Cu}-\mathrm{H}$ but also the $\mathrm{SiO}-\mathrm{H}$ are involved in the TS1 state as well as TS5 on $\mathrm{SiO}_{2} / \mathrm{Cu}(111)$. It was expected that when hydrogen was replaced by deuterium, the vibrations of both $\mathrm{Cu}-\mathrm{D}$ and $\mathrm{SiO}-\mathrm{D}$ would contribute to the zero-point energy of TS', leading to a large KIE. It is particularly interesting that, when $\mathrm{Cu} \mathrm{MPs@m-SiO}{ }_{2}$ was treated by a $\mathrm{NaOH}$ solution, $\mathrm{Na}^{+}$ions pre-occupies the $\mathrm{Cu}-\mathrm{SiO}$ sites so that the formation of $\mathrm{SiO}-\mathrm{H}$ should be suppressed during the hydrogenation. As expected, the TOF for the $\mathrm{NaOH}$-treated $\mathrm{Cu} \mathrm{MPs} @ \mathrm{~m}-\mathrm{SiO}_{2}$ catalyst was decreased dramatically to a similar level to that of uncoated Cu MPs, and the KIE was also dropped back to 1.6 (Supplementary Fig. 7). With the combination of DFT calculation and isotope-labelling experiments, we conclude that the $\mathrm{Cu}-\mathrm{O}-\mathrm{SiO}_{x}$ interface not only activates $\mathrm{H}_{2}$ molecules in the heterolytic way to form $\mathrm{Cu}-\mathrm{H}^{\delta-}$ and $\mathrm{SiO}-\mathrm{H}^{\delta+}$, but also facilitates the hydrogenation of ester by stablizing the transition states.

Nanostructure engineering enriches the $\mathrm{Cu}-\mathrm{O}-\mathrm{SiO}_{x}$ interfaces. As the promotional effect induced by the $\mathrm{Cu}-\mathrm{O}-\mathrm{SiO}_{x}$ interface, increasing $\mathrm{Cu}-\mathrm{O}-\mathrm{SiO}_{x}$ interfaces should lead to further enhanced catalytic efficiency. Thus, reducing the size of $\mathrm{Cu}$ particles to the nanoscale would amplify the interfacial effect. To create $\mathrm{Cu}-\mathrm{SiO}_{2}$ interface on $\mathrm{Cu}$ nanoparticles, $\mathrm{Cu}_{2} \mathrm{O}$ nanoparticles were first prepared and coated by $\mathrm{m}-\mathrm{SiO}_{2}$ (Fig. 3a). The obtained $\mathrm{Cu}_{2} \mathrm{O} @ \mathrm{~m}-\mathrm{SiO}_{2}$ nanoparticles were then reduced under $\mathrm{H}_{2}$ atmosphere to convert into $\mathrm{Cu} @ \mathrm{~m}-\mathrm{SiO}_{2}$ nanoparticles (denoted as $\mathrm{Cu}-\mathrm{NP} @ \mathrm{~m}-\mathrm{SiO}_{2}$ ). Comprehensive characterizations by TEM, EDS, XRD (Fig. 3b-h), and $\mathrm{N}_{2}$ adsorption/desorption isotherms (Supplementary Fig. 8) confirmed the core-shell structure of $\mathrm{Cu}$ $\mathrm{NP} @ \mathrm{~m}-\mathrm{SiO}_{2}$. As expected, the as-prepared $\mathrm{Cu}-\mathrm{NP} @ \mathrm{~m}-\mathrm{SiO}_{2}$ catalyst exhibited a much better catalytic performance in DMO hydrogenation than unmodified $\mathrm{Cu}$ NPs (Fig. 3i). With a liquid hourly space velocity (LHSV) of $2.4 \mathrm{~h}^{-1}, \mathrm{Cu}-\mathrm{NP} @ \mathrm{~m}-\mathrm{SiO}_{2}$ exhibited both much higher DMO conversion (95.8\%) and higher selectivity $\left(93.3 \%\right.$ to EG) at $200{ }^{\circ} \mathrm{C}$. In contrast, when $\mathrm{Cu} \mathrm{NPs}$ were used as the catalyst, only $35.6 \%$ of DMO was hydrogenated with $16.9 \%$ of selectivity to EG.

In term of $\mathrm{Cu}$ utilization, the core-shell overgrowth structure $\left(\mathrm{Cu}-\mathrm{NP} @ \mathrm{~m}-\mathrm{SiO}_{2}\right)$ demonstrated above was not the ideal structure for practical applications because most of $\mathrm{Cu}$ atoms in $\mathrm{Cu}-\mathrm{NP} @ \mathrm{~m}-\mathrm{SiO}_{2}$ were not located on surface or $\mathrm{Cu}-\mathrm{O}-\mathrm{SiO}_{x}$ interfaces. In this regard, encapsulating ultra-small $\mathrm{Cu}$ nanoparticles in a porous $\mathrm{SiO}_{2}$ matrix should be the most effective strategy to create highly active catalysts while maximizing the utilization of $\mathrm{Cu}$. For this purpose, we chose copper phyllosilicate nanotubes as an alternative $\mathrm{Cu}$ precursor. Structurally, copper phyllosilicate has lamellar structure composed of alternate layers of $\mathrm{SiO}_{4}$ tetrahedra and discontinuous layers of $\mathrm{CuO}_{6}$ octahedra, in which $\mathrm{Cu}-\mathrm{O}-\mathrm{SiO}_{x}$ moieties are readily available (Supplementary Fig. 9) ${ }^{35-39}$. By using a modified hydrothermal method, copper phyllosilicate nanotubes (Cu-PSNT) with sub-10 $\mathrm{nm}$ in diameter, 1-2 $\mathrm{nm}$ in wall thickness, and hundreds of nanometers in length were prepared (Fig. 4b). Both TEM and EDS analysis (Fig. 4c, Supplementary Fig. 10) confirmed the formation of metallic $\mathrm{Cu}$ nanoparticles which were embedded in $\mathrm{SiO}_{2}$ matrix after the $\mathrm{H}_{2}$ reduction. Some large $\mathrm{Cu}$ nanoparticles with size larger than $10 \mathrm{~nm}$ were also observed. Moreover, the BET analysis (Supplementary Fig. 11) revealed that the reduced $\mathrm{Cu}$ PSNT had a BET surface area of $470.1 \mathrm{~m}^{2} \mathrm{~g}^{-1}$ and a pore volume of $1.47 \mathrm{~cm}^{3} \mathrm{~g}^{-1}$.
To demonstrate the advantages of the reduced $\mathrm{Cu}-\mathrm{PSNT}$ in catalysis, a $\mathrm{Cu} / \mathrm{SiO}_{2}$ catalyst (denoted as $\mathrm{Cu} / \mathrm{SiO}_{2}-\mathrm{AE}$, Supplementary Fig. 12) was prepared by a reported ammoniaevaporation method for comparison ${ }^{38,40-42}$. The $\mathrm{Cu} / \mathrm{SiO}_{2}-\mathrm{AE}$ catalyst represents the state-of-the-art $\mathrm{Cu}$ catalyst reported in the literature for the selective hydrogenation of DMO to EG $\mathrm{EG}^{29,43-45}$. Although $\mathrm{Cu}$ nanoparticles in the reduced $\mathrm{Cu}-\mathrm{PSNT}$ had an average size larger than that in the reduced $\mathrm{Cu} / \mathrm{SiO}_{2}-\mathrm{AE}$ (Supplementary Fig. 13), what particularly interesting is that, the reduced $\mathrm{Cu}$-PSNT exhibited both much better activity and selectivity than the reduced $\mathrm{Cu} / \mathrm{SiO}_{2}-\mathrm{AE}$ (Supplementary Fig. 14). At $200{ }^{\circ} \mathrm{C}$, the reduced $\mathrm{Cu}-\mathrm{PSNT}$ showed $99.8 \%$ conversion of DMO as well as $97.9 \%$ selectivity to EG with a LHSV as high as $4.2 \mathrm{~h}^{-1}$. In contrast, under the same reaction conditions, the reduced $\mathrm{Cu} / \mathrm{SiO}_{2}-\mathrm{AE}$ catalyst gave only $76.2 \%$ conversion of DMO and $68.9 \%$ selectivity to EG. It should be noted that, even after long time $(24 \mathrm{~h})$ catalysis, $\mathrm{Cu}$ nanoparticles in the reduced $\mathrm{Cu} / \mathrm{SiO}_{2}-\mathrm{AE}$ catalyst did not sinter much and were still smaller than those in the reduced Cu-PSNT catalyst (Supplementary Fig. 13).

The above catalysis comparison between $\mathrm{Cu}-\mathrm{PSNT}$ and $\mathrm{Cu} /$ $\mathrm{SiO}_{2}$-AE clearly indicated that the particle size of $\mathrm{Cu}$ was not the predominant factor to determine the catalytic performance. The enhanced performance should be attributed to the presence of more abundant $\mathrm{Cu}-\mathrm{O}-\mathrm{SiO}_{x}$ interfaces in the reduced $\mathrm{Cu}-\mathrm{PSNT}$ than $\mathrm{Cu} / \mathrm{SiO}_{2}$-AE. In principle, the presence of abundant $\mathrm{Cu}-\mathrm{O}-\mathrm{SiO}_{x}$ interfaces should result in the presence of more $\mathrm{Cu}^{\delta+}$ species in the reduced $\mathrm{Cu}-\mathrm{PSNT}$. While XPS measurements confirmed the reduction of $\mathrm{Cu}^{2+}$ in both reduced $\mathrm{Cu}-\mathrm{PSNT}$ and $\mathrm{Cu} / \mathrm{SiO}_{2}$-AE composite (Supplementary Fig. 15), the $\mathrm{Cu} \mathrm{LMM}$ XAES studies demonstrated that the $\mathrm{Cu}^{+} / \mathrm{Cu}^{0}$ ratios were much different in the two catalysts. Two overlapping peaks at $914.1 \mathrm{eV}$ and $917.8 \mathrm{eV}$ were ascribed to $\mathrm{Cu}^{+}$and $\mathrm{Cu}^{0}$, respectively. ${ }^{28,46,47}$ The ratio of $\mathrm{Cu}^{+} / \mathrm{Cu}^{0}$ was 0.65 (Table S1) for the reduced $\mathrm{Cu}$ PSNT, 1.2 times higher than that of the reduced $\mathrm{Cu} / \mathrm{SiO}_{2}-\mathrm{AE}$ catalyst (0.55). The high percentage of $\mathrm{Cu}^{+}$confirmed the presence of more $\mathrm{Cu}-\mathrm{O}-\mathrm{SiO}_{x}$ interfaces in the reduced $\mathrm{Cu}-\mathrm{PSNT}$ catalyst, consistent with our proposal that the $\mathrm{Cu}-\mathrm{O}-\mathrm{SiO}_{x}$ interface was the determining factor for the catalysis.

Maximizing both $\mathrm{Cu}-\mathrm{O}-\mathrm{SiO}_{x}$ interfaces and $\mathrm{Cu}$ utilization. It should be noted that the simple reduction did not maximize the use of $\mathrm{Cu}$ due to the formation of some large $\mathrm{Cu}$ nanoparticles with size larger than $10 \mathrm{~nm}$ (Fig. 4c). There was still possibility to further improve the catalytic performance of $\mathrm{Cu}-\mathrm{PSNT}$ if one could reduce the particle size of $\mathrm{Cu}$ nanoparticles during the $\mathrm{H}_{2}$ treatment. To achieve this goal, our strategy was to encapsulate $\mathrm{Cu}-\mathrm{PSNT}$ with a thin layer of $\mathrm{m}-\mathrm{SiO}_{2}$. The mesoporous layer $\mathrm{SiO}_{2}$ was used to prevent the sintering of $\mathrm{Cu}$ nanoparticles during the $\mathrm{H}_{2}$ treatment and also to create more $\mathrm{Cu}-\mathrm{O}-\mathrm{SiO}_{x}$ interfaces. The coating of the $\mathrm{m}-\mathrm{SiO}_{2}$ shell was carried out by hydrolysis of TEOS in the presence of CTAB (Fig. 4a, See Methods section $)^{48}$. In the as-obtained core-shell material (denoted as Cu-PSNT@m-SiO ${ }_{2}$ ), the successful growth of a wormhole-like $\mathrm{m}-\mathrm{SiO}_{2}$ shell on $\mathrm{Cu}-\mathrm{PSNT}$ was revealed by TEM analysis (Fig. $4 \mathrm{~d}$ ), and also confirmed by $\mathrm{N}_{2}$ adsorption/desorption measurement (Supplementary Fig. 16). Compared with $\mathrm{Cu}-\mathrm{PSNT}$, the BET surface area of Cu-PSNT@m-SiO 2 was increased to $605.5 \mathrm{~m}^{2} \mathrm{~g}^{-1}$.

As expected, the $\mathrm{SiO}_{2}$ coating on $\mathrm{Cu}-\mathrm{PSNT}$ significantly prevented $\mathrm{Cu}$ nanoparticles from sintering during the $\mathrm{H}_{2}$ treatment as revealed by TEM and XRD studies (Fig. 4e, Supplementary Fig. 17a). After $4-\mathrm{h} \mathrm{H}_{2}$ treatment at $300^{\circ} \mathrm{C}$, the XRD and XPS results confirmed the reduction of $\mathrm{Cu}(\mathrm{II})$ in $\mathrm{Cu}$ PSNT@m-SiO 2 into fine fcc Cu nanoparticles (Supplementary 
a

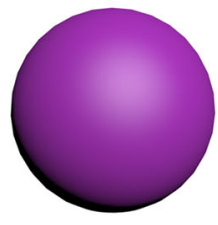

$\mathrm{Cu}_{2} \mathrm{O}$
TEOS, CTAB

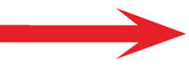

Silica coating

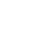

\section{.}
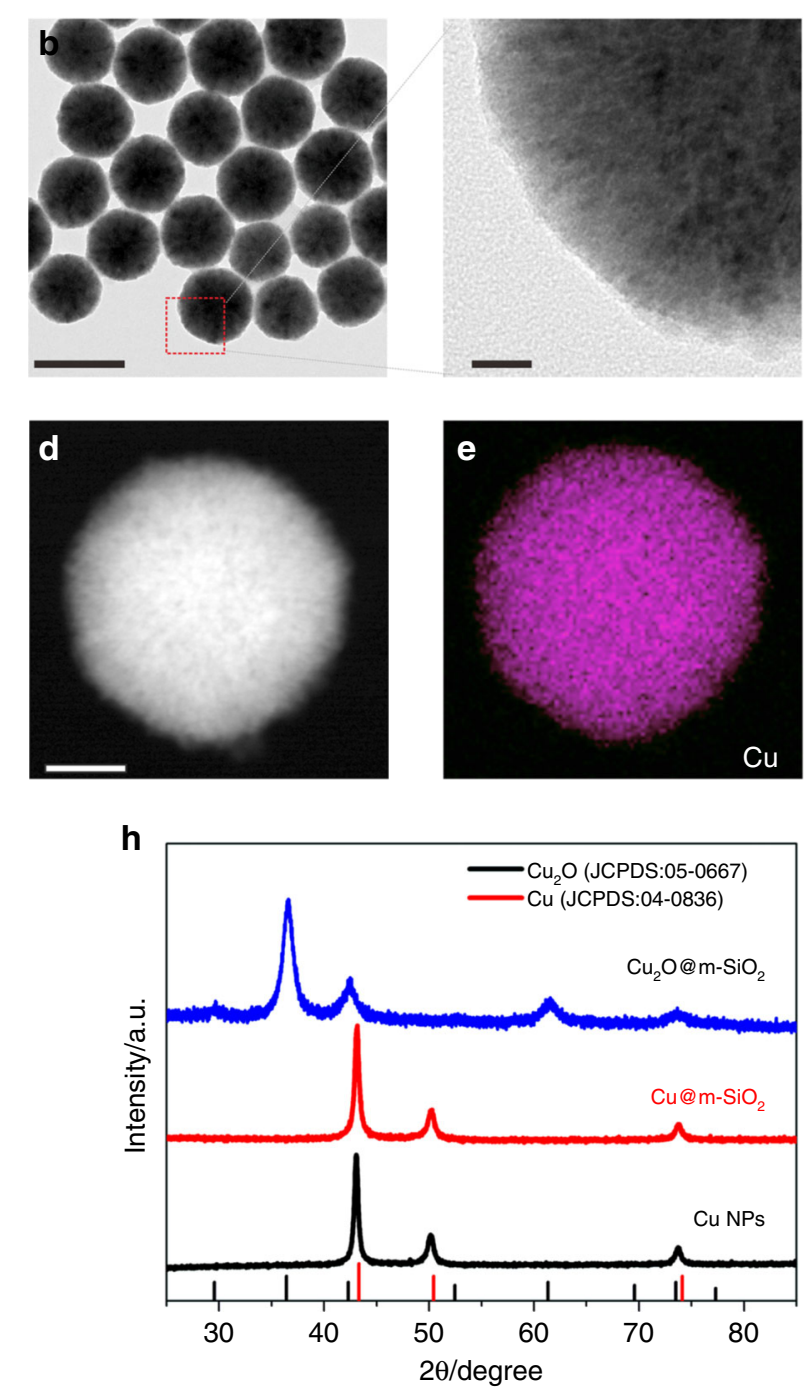

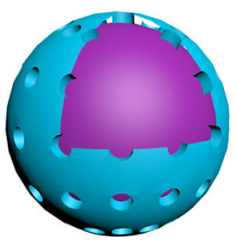

$\mathrm{Cu}_{2} \mathrm{O} @ \mathrm{~m}-\mathrm{SiO}_{2}$

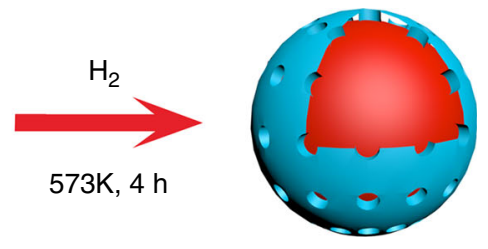

Cu-NP@m-SiO 2
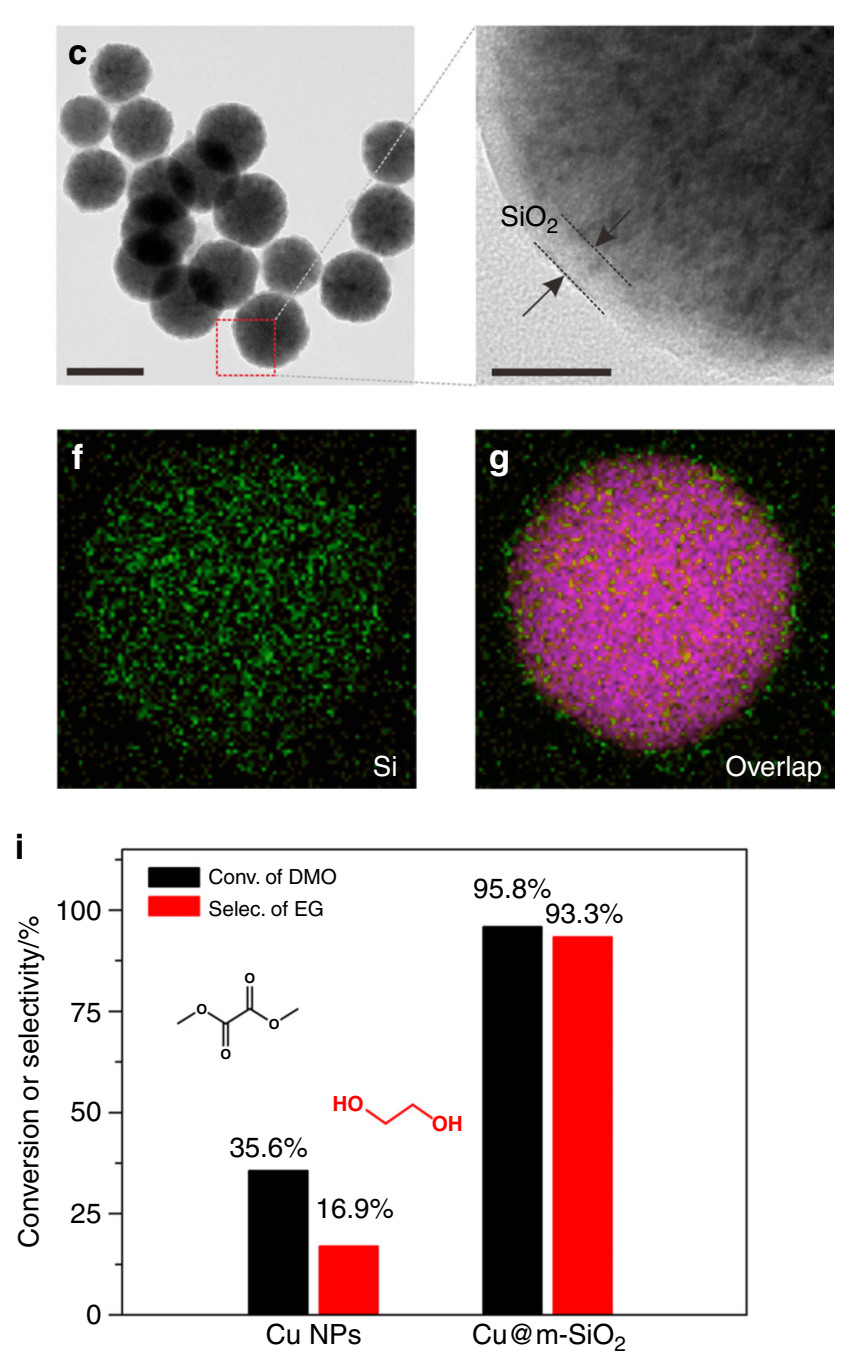

Fig. 3 Creating $\mathrm{Cu}-\mathrm{O}-\mathrm{SiO}_{x}$ interfaces on $\mathrm{Cu}$ nanoparticles. a Scheme for the synthesis of $\mathrm{Cu} @ m-\mathrm{SiO}_{2} ; \mathbf{b}, \mathbf{c}$ TEM images of as-prepared $\mathrm{Cu} \mathrm{H}_{2} \mathrm{O}$ nanoparticles and $\mathrm{Cu}_{2} \mathrm{O} @ m-\mathrm{SiO}_{2}$, respectively. d-g EDX mapping images of $\mathrm{Cu}_{2} \mathrm{O} @ m-\mathrm{SiO}_{2} ; \mathbf{h}$ X-ray powder diffraction (XRD) pattern of $\mathrm{Cu}_{\mathrm{NPs}} \mathrm{Cu}_{2} \mathrm{O} @ m-\mathrm{SiO} 2$ and $\mathrm{Cu} @ \mathrm{~m}-\mathrm{SiO}_{2} ; \mathbf{i}$ Catalytic performance of $\mathrm{Cu} \mathrm{NPs}$ and $\mathrm{Cu} @ \mathrm{~m}-\mathrm{SiO}_{2}$ for the selective hydrogenation of DMO; Reaction conditions were as follows: $\mathrm{H}_{2} / \mathrm{DMO}=80 \mathrm{~mol} / \mathrm{mol}, \mathrm{P}\left(\mathrm{H}_{2}\right)=3.0 \mathrm{MPa}, \mathrm{T}=200^{\circ} \mathrm{C}, \mathrm{LHSV}=2.4 \mathrm{~h}^{-1}$. Scale bars in b (left) and c (left) are $200 \mathrm{~nm}$. Scale bars in b (right) and c (right) are $20 \mathrm{~nm}$. Scale bar in $\mathbf{d}$ is $50 \mathrm{~nm}$

Figs. 15 and 17a). The yielded $\mathrm{Cu}$ nanoparticles were even too small to be clearly detected by TEM and STEM (Fig. 4e and Supplementary Fig. 17b) due to the limited electronic contrast between $\mathrm{Cu}$ and $\mathrm{SiO}_{2}$. No formation of large $\mathrm{Cu}$ nanoparticles with size larger than $2 \mathrm{~nm}$ was observed in the reduced $\mathrm{Cu}$ PSNT@m-SiO ${ }_{2}$ catalyst, dramatically different from the reduced $\mathrm{Cu}$-PSNT. As determined by ICP-AES, the $\mathrm{Cu}$ content in $\mathrm{Cu}-$ PSNT@m- $\mathrm{SiO}_{2}$ was as high as $20.5 \mathrm{wt} \%$ (Supplementary Table 2). More importantly, the ratio of $\mathrm{Cu}^{+} / \mathrm{Cu}^{0}$ demonstrated by $\mathrm{Cu}$ LMM XAES spectra is 0.99 (Supplementary Fig. 15 and Supplementary Table 1), 1.5 and 1.8 times higher than those of $\mathrm{Cu}-\mathrm{PSNT}$ and $\mathrm{Cu} / \mathrm{SiO}_{2}-\mathrm{AE}$ catalysts. These results suggested that $\mathrm{Cu}$ in reduced Cu-PSNT@m-SiO $\mathrm{S}_{2}$ were present mainly in the form of ultrafine nanoparticles confined in the $\mathrm{SiO}_{2}$ matrix. The confinement of fine $\mathrm{Cu}$ nanoparticles in porous $\mathrm{SiO}_{2}$ was expected to create abundant $\mathrm{Cu}-\mathrm{O}-\mathrm{SiO}_{x}$ interfaces to boost the hydrogenation. In situ FT-IR measurements over the reduced $\mathrm{Cu}$ PSNT@m- $\mathrm{SiO}_{2}$ catalyst under $\mathrm{D}_{2}$ atmosphere revealed the formation of SiO-D (Supplementary Fig. 18), further confirming the heterolytic activation pathway of $\mathrm{D}_{2}$ over the $\mathrm{Cu}-\mathrm{O}-\mathrm{SiO}_{x}$ interfaces.

As compared to the reduced Cu-PSNT catalyst with the same amount of $\mathrm{Cu}$, the catalytic performance of the reduced $\mathrm{Cu}-\mathrm{PSNT} @ \mathrm{~m}-\mathrm{SiO}_{2}$ catalyst was greatly enhanced in both activity 
a

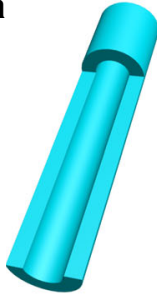

Cu-PSNT

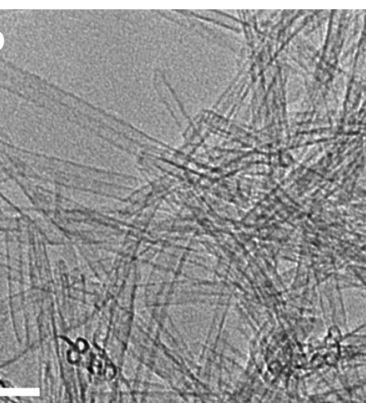

c.

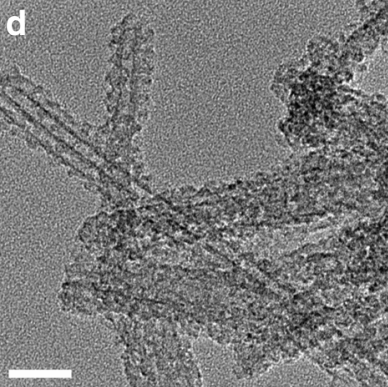

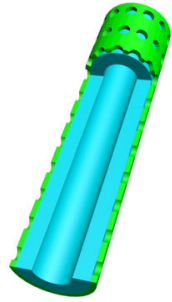

Cu-PSNT@m-SiO 2
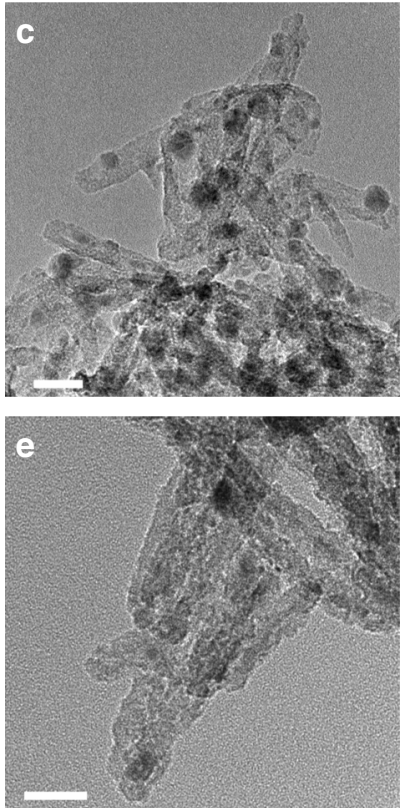

Reduced

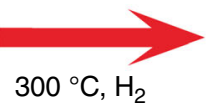

$300{ }^{\circ} \mathrm{C}, \mathrm{H}_{2}$

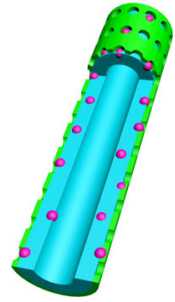

Reduced Cu-PSNT@m-SiO 2

f

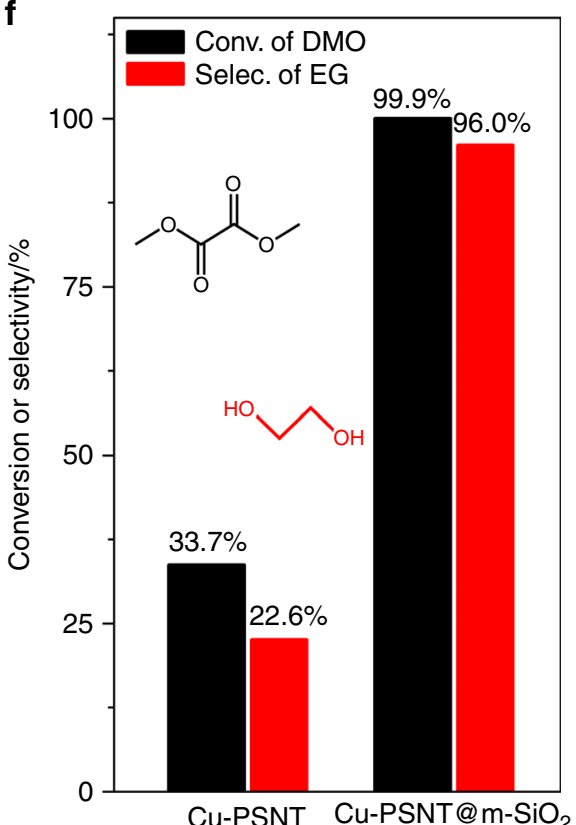

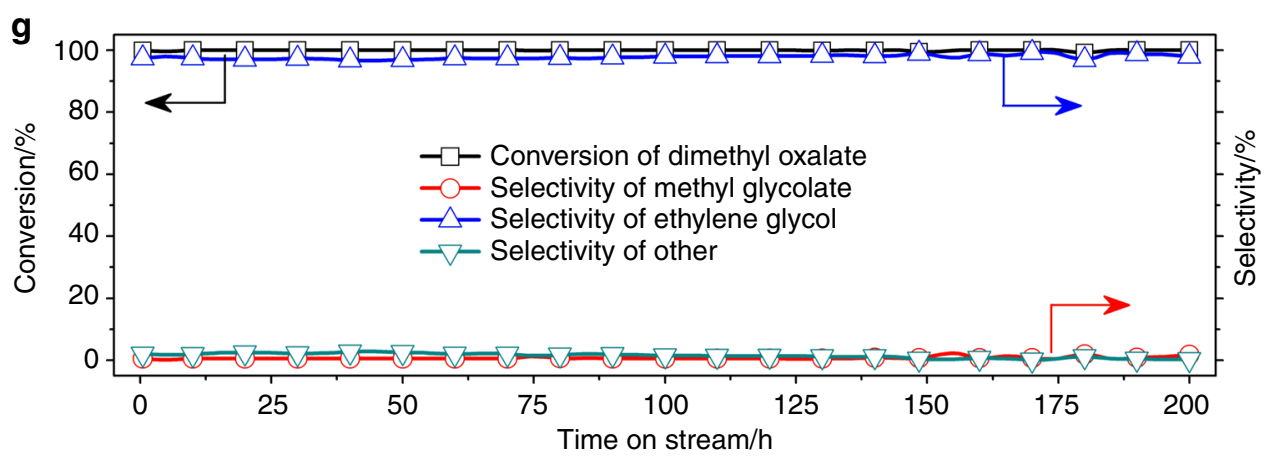

Fig. 4 Confined growth strategy for maximizing $\mathrm{Cu}-\mathrm{O}-\mathrm{SiO}_{x}$ interface. a Illustration of the synthetic strategy for the preparation of $\mathrm{Cu}-\mathrm{PSNT} @ \mathrm{~m}-\mathrm{SiO}{ }_{2}$; b-e TEM image of as-prepared Cu-PSNT, reduced Cu-PSNT, Cu-PSNT@m-SiO 2 and reduced Cu-PSNT@m-SiO ${ }_{2}$, respectively; $\mathbf{f}$ Catalytic performance of reduced Cu-PSNT and reduced Cu-PSNT@ $\mathrm{m}-\mathrm{SiO}_{2}$ for the selective hydrogenation of DMO to EG (LHSV=7.8 $\mathrm{h}^{-1}$ ); $\mathbf{g}$ Catalytic performance of reduced Cu-PSNT@m-SiO 2 catalyst as a function of time-on-stream $\left(\mathrm{LHSV}=2.0 \mathrm{~h}^{-1}\right.$ ). Reaction conditions were as follows: $\mathrm{H}_{2} / \mathrm{DMO}=80 \mathrm{~mol} / \mathrm{mol}$, $P\left(\mathrm{H}_{2}\right)=3.0 \mathrm{MPa}, T=200^{\circ} \mathrm{C}$. Scale bars are $20 \mathrm{~nm}$ for $(\mathbf{b}-\mathbf{e})$

and selectivity for DMO hydrogenation to EG. As shown in Fig. 4f, a nearly $100 \%$ conversion of DMO and a high selectivity of $96.0 \%$ to EG were achieved over the reduced Cu-PSNT@m$\mathrm{SiO}_{2}$ catalyst even at a LHSV as high as $7.8 \mathrm{~h}^{-1}$ at $200^{\circ} \mathrm{C}$. Under the same catalytic conditions (high LHSV), the reduced Cu-PSNT only gave $33.7 \%$ conversion of DMO and $22.6 \%$ selectivity to EG. The TOF (Supplementary Table 2) of the reduced Cu-PSNT@m$\mathrm{SiO}_{2}$ catalyst $\left(40.62 \mathrm{~h}^{-1}\right)$ was much higher than that of the reduced $\mathrm{Cu}-\mathrm{PSNT}\left(23.08 \mathrm{~h}^{-1}\right)$ or $\mathrm{Cu} / \mathrm{SiO}_{2}-\mathrm{AE}\left(10.21 \mathrm{~h}^{-1}\right)$ catalyst. More importantly, after catalysis studies at different LHSVs, no formation of large $\mathrm{Cu}$ nanoparticles caused by sintering was observed over the reduced Cu-PSNT@m- $\mathrm{SiO}_{2}$ catalyst (Supplementary Fig. 19). The reduced Cu-PSNT@m-SiO also displayed excellent stability in the time-on-stream experiment (Fig. 4g). No decay in the activity and stability of the reduced Cu-PSNT@m-SiO ${ }_{2}$ catalyst was observed even after the $200 \mathrm{~h}$ time-on-stream (LHSV $=2.0 \mathrm{~h}^{-1}$ ) experiment. Additionally, the reduced Cu-PSNT@m-SiO 2 also displayed excellent stability in ultra-high temperature and ultra-high LHSV (Supplementary Fig. 20). At $280{ }^{\circ} \mathrm{C}$, the reduced $\mathrm{Cu}-\mathrm{PSNT} @ m-\mathrm{SiO}_{2}$ exhibited $\sim 95 \%$ conversion of DMO as well as $\sim 90 \%$ selectivity of EG with a LHSV as high as $300 \mathrm{~h}^{-1}$ during the long time $(16 \mathrm{~h})$ catalysis. To the best of our knowledge, the catalytic activity of the reduced $\mathrm{Cu}-\mathrm{PSNT} @ \mathrm{~m}-\mathrm{SiO}_{2}$ showed the best performance among reported copper-based catalysts for ester hydrogenation (Supplementary Table 3). 
Although $\mathrm{SiO}_{2}$ has been long considered as an inert support to create active metal-support interface for promoting catalysis, we demonstrate in this work that $\mathrm{Cu}-\mathrm{O}-\mathrm{SiO}_{x}$ is a very active interface in selective hydrogenation of DMO to EG. The activity of silica-coated $\mathrm{Cu}$ catalysts with $\mathrm{Cu}-\mathrm{O}-\mathrm{SiO}_{x}$ interfaces in selective hydrogenation of DMO is approximately 80 times higher than that on pristine $\mathrm{Cu}$ at the temperature between 200 and $240{ }^{\circ} \mathrm{C}$. With the combination of DFT calculations and isotope-labelling experiments, the catalytic mechanism on $\mathrm{Cu}-\mathrm{O}-\mathrm{SiO}_{x}$ interface has been well clarified. The existence of $\mathrm{Cu}-\mathrm{H}^{\delta-}$ and $\mathrm{SiO}-\mathrm{H}^{\delta+}$ at $\mathrm{Cu}-\mathrm{O}-\mathrm{SiO}_{x}$ interfaces would facilitate the hydrogenation of ester by stablizing the hydrogenation transition states. Based on this mechanism, we develped a confined growth strategy to maximize $\mathrm{Cu}-\mathrm{O}-\mathrm{SiO}_{x}$ interfaces and $\mathrm{Cu}$ utilization. By coating copper phyllosilicate nanotubes with mesoporous silica followed by hydrogen reduction, a practical $\mathrm{Cu}$ nanocatalyst was produced and possessed abundant $\mathrm{Cu}-\mathrm{O}-\mathrm{SiO}_{x}$ interfaces and thus exhibited the best performance in the hydrogenation of DMO to EG among all reported $\mathrm{Cu}$ catalysts. We envision that the discovery of the active $\mathrm{Cu}-\mathrm{O}-\mathrm{SiO}_{x}$ interface for promoting catalysis in this work will lead us to revisit the support effects of $\mathrm{SiO}_{2}$ and create pratical $\mathrm{SiO}_{2}$-supported metal nanocatalysts with enhanced catalytic activity, selectivity, and durability.

\section{Methods \\ Materials. Colloidal silica (Ludox- $\mathrm{HS} 40, \mathrm{SiO}_{2} 40$ wt \% aqueous solution),} methanol and tetraethyl orthosilicate were purchased from Alfa Aesar Chemical Reagent Co. Ltd. (Tianjin, China). $\mathrm{Cu}\left(\mathrm{NO}_{3}\right)_{2} \cdot 3 \mathrm{H}_{2} \mathrm{O}, \mathrm{DMO}, \mathrm{CuCl}_{2} \cdot 2 \mathrm{H}_{2} \mathrm{O}$, ammonium chloride, ethanol, $\mathrm{N}$-hexadecyltrimethylammonium bromide and ammonia aqueous solution (25\% 28\%) were purchased from Sinopharm Chemical Reagent Co. Ltd. (Shanghai, China). Cu powder was purchased from Tianjin Guangfu Fine Chemical Co., Ltd. Deuterium gas (99.999\%) was purchased from Chengdu Keyuan Gas Co. Ltd. All reagents were used as received without further purification. Water used in the studies was ultrapure water (Millipore, $\geq 18 \mathrm{M} \Omega \mathrm{cm}$ )

Synthesis of cuprous oxide nanoparticles $\left(\mathrm{Cu}_{\mathbf{2}} \mathbf{O} \mathbf{~ N P s}\right) . \mathrm{Cu}_{2} \mathrm{O}$ NPs were prepared by using the high-temperature ploy-mediated methods reported by Zeng ${ }^{49}$. In a typical synthesis of $\mathrm{Cu}_{2} \mathrm{O}$ NPs, $0.5 \mathrm{mmol}$ of $\mathrm{Cu}\left(\mathrm{NO}_{3}\right)_{2} \cdot 3 \mathrm{H}_{2} \mathrm{O}$ and $1.0 \mathrm{~g}$ of PVP were dissolved in $10 \mathrm{~mL}$ of DEG. The mixed solution was heated from room temperature to $190^{\circ} \mathrm{C}$ in $0.5 \mathrm{~h}$ under argon atmosphere. The products were collected by centrifugation and washed with ethanol for several times. Finally, the products were dispersed in ethanol for further use.

Synthesis of $\mathrm{Cu}_{2} \mathrm{O}$ NPs coated with mesoporous silica. $\mathrm{Cu}_{2} \mathrm{O} @ m-\mathrm{SiO}_{2}$ were prepared by using the modified method reported by Fang ${ }^{50}$. In a typical synthesis of $\mathrm{Cu}_{2} \mathrm{O} @ \mathrm{~m}-\mathrm{SiO}_{2}, 0.2 \mathrm{~g}$ of $\mathrm{Cu}_{2} \mathrm{O}$ NPs and $1 \mathrm{~g}$ of CTAB were added into $200 \mathrm{~mL}$ water in flask under argon atmosphere and then transferred to a $45^{\circ} \mathrm{C}$ water bath. Then, $5 \mathrm{~mL}$ of ethanol and $0.4 \mathrm{~mL}$ of TEOS were added into above mixture and stirred for another $30 \mathrm{~min}$. The products were collected by centrifugation and washed with ethanol several times. The method of extraction was used to remove CTAB from the products. Briefly, the products were dispersed in $100 \mathrm{~mL}$ of acetone and refluxed at $80^{\circ} \mathrm{C}$ for $8 \mathrm{~h}$. The extraction was repeated three times to fully remove CTAB. Finally, the products were collected by centrifugation and washed with ethanol several times.

Synthesis of copper phyllosilicate nanotubes. Copper phyllosilicate nanotubes (Cu-PSNT) were prepared by a hydrothermal method. Typically, $6.5 \mathrm{mmol}$ of copper (II) salt $\left(\mathrm{CuCl}_{2} \cdot 2 \mathrm{H}_{2} \mathrm{O}\right.$ or $\left.\mathrm{Cu}\left(\mathrm{NO}_{3}\right)_{2} \cdot 3 \mathrm{H}_{2} \mathrm{O}\right)$ and $26 \mathrm{mmol}$ of $\mathrm{NH}_{4} \mathrm{Cl}$ were dissolved in $60 \mathrm{~mL}$ water, into which $5 \mathrm{~mL}$ of $\mathrm{NH}_{3} \cdot \mathrm{H}_{2} \mathrm{O}$ was added to form a blue solution. Then, $1 \mathrm{~g}$ of silica colloidal $\left(\mathrm{SiO}_{2} 40 \mathrm{wt} \%\right)$ was added into above solution. Subsequently, the mixture was transferred into $100 \mathrm{~mL}$ capacity Teflon-lined stainless steel autoclave and then the autoclave was put in an oven at $200^{\circ} \mathrm{C}$ for $48 \mathrm{~h}$. The blue products were collected by centrifugation and washed with water for several times. Finally, the blue products were dried in a vacuum oven at $60^{\circ} \mathrm{C}$ for $12 \mathrm{~h}$.

Synthesis of Cu-PSNT coated with mesoporous silica. Cu-PSNT@m- $\mathrm{SiO}_{2}$ was prepared using the modified method reported by Fang ${ }^{50}$. For a typical synthesis of Cu-PSNT@m-SiO $2,0.6 \mathrm{~g}$ of copper phyllosilicate nanotubes was dispersed into $200 \mathrm{~mL}$ water containing $1 \mathrm{~g}$ of CTAB in the flask. The mixture was transferred to a $45^{\circ} \mathrm{C}$ water bath and then ethanol $(5 \mathrm{~mL})$ and TEOS $(2 \mathrm{~mL})$ were added. After 30 min, the products were collected by centrifugation and washed with ethanol several times. Subsequently, the products were dried in a vacuum oven at $60^{\circ} \mathrm{C}$ for $12 \mathrm{~h}$ Calcination was used to remove $\mathrm{CTAB}$ and the products were heated to $500^{\circ} \mathrm{C}$ $\left(2^{\circ} \mathrm{C} / \mathrm{min}\right)$ for $2 \mathrm{~h}$ in air.

Synthesis of the $\mathrm{Cu} / \mathrm{SiO}_{2}-\mathrm{AE}$ catalyst. $\mathrm{Cu} / \mathrm{SiO}_{2}-\mathrm{AE}$ was prepared by ammonia evaporation method ${ }^{38}$. The ammonia evaporation method was described as follows: $3.05 \mathrm{~g}$ of $\mathrm{Cu}\left(\mathrm{NO}_{3}\right)_{2} \cdot 3 \mathrm{H}_{2} \mathrm{O}$ was dissolved in a mixture of ultrapure water $(75 \mathrm{~mL})$ and ammonia aqueous $(5 \mathrm{~mL})$. Then, $20 \mathrm{~g}$ of silica colloidal $\left(\mathrm{SiO}_{2} 40 \mathrm{wt} \%\right)$ was added into above copper ammonia complex solution. Subsequently, the mixed solution was heated in an $85^{\circ} \mathrm{C}$ water bath to evaporate ammonia. As the process continues, the $\mathrm{pH}$ value of the mixture decreased slowly. When the $\mathrm{pH}$ value decreased below 7.0, the products were collected by centrifugation and washed with water for several times. Finally, the products were dried in an oven at $60^{\circ} \mathrm{C}$ for $12 \mathrm{~h}$ and then were heated to $500^{\circ} \mathrm{C}\left(2^{\circ} \mathrm{C}\right.$ per min) for $2 \mathrm{~h}$ in air.

Characterizations. Transmission electron microscopy (TEM) images were taken on a TECNAI F-30 high-resolution transmission electron microscope operating at $300 \mathrm{kV}$. The conventional and in situ X-ray powder diffraction (XRD) were performed with PANalytical X'pert PRO diffractometer using $\mathrm{Cu} \mathrm{K}$ a radiation $(\lambda=$ $0.15418 \mathrm{~nm}$ ), operating at $40 \mathrm{kV}$ and $30 \mathrm{~mA}$. For the in situ XRD measurement, the samples were put in an in situ chamber and $5 \% \mathrm{H}_{2}-95 \% \mathrm{~N}_{2}$ mixture gas was introduced to the system at a flow rate of $50 \mathrm{~mL}$ per min. Then, the sample was heated to $573 \mathrm{~K}\left(2^{\circ} \mathrm{C}\right.$ per min) for $4 \mathrm{~h}$. When the temperature of sample cooled to room temperature, the XRD patterns were collected. $\mathrm{N}_{2}$ adsorption-desorption measurements were carried on a Micrometrics ASAP 2020 system. Pore size distributions were calculated from desorption branch by the Barrett-Joyner-Halenda (BJH) method. The total pore volume depended on the desorption $\mathrm{N}_{2}$. X-ray photoelectron spectroscopy (XPS) and X-ray induced Auger electron spectroscopy (XAES) were obtained using a PHI Quantum 2000 Scanning ESCA Microprobe instrument (physical Electronics) equipped with an $\mathrm{Al} \mathrm{Ka} \mathrm{X-ray} \mathrm{source} \mathrm{(} h v=$ $1486.6 \mathrm{eV})$ and binding energies referenced to $\mathrm{C} 1 \mathrm{~s}(284.8 \mathrm{eV})$. For quasi-in situ XPS measurement, the samples were treated with $5 \% \mathrm{H}_{2}-95 \% \mathrm{~N}_{2}(573 \mathrm{~K}-4 \mathrm{~h})$ in an in situ chamber, and then evacuated to obtain a high vacuum environment. Finally, the reduced samples were transferred from in situ chamber to testing chamber under vacuum conditions. The precise copper content of sample was determined by the inductively coupled plasma atomic emission spectroscopy (ICP-AES, Baird PS-4). The copper dispersions of the samples were measured by $\mathrm{N}_{2} \mathrm{O}$ titration on a Micromeritics Autochem II 2920 apparatus with a TCD. Typical steps as follows: (1) Samples were reduced in a $5 \% \mathrm{H}_{2}-95 \% \mathrm{~N}_{2}$ atmosphere ( $50 \mathrm{~mL}$ per min) at $573 \mathrm{~K}$ for $4 \mathrm{~h}$ (hydrogen consumption was denoted as $A_{1}$ ) and then cooled down to $333 \mathrm{~K}$ in argon atmosphere. (2) The surface copper atoms were oxidized to $\mathrm{Cu}_{2} \mathrm{O}$ by $\mathrm{N}_{2} \mathrm{O}$ $(30 \mathrm{~mL} / \mathrm{min}$ ) for $0.5 \mathrm{~h}$ and then the argon was introduced to the system for $0.5 \mathrm{~h}$ to remove the $\mathrm{N}_{2} \mathrm{O}$. (3) The reduction of surface $\mathrm{Cu}_{2} \mathrm{O}$ to copper was carried out by a $5 \% \mathrm{H}_{2}-95 \% \mathrm{~N}_{2}$ mixture gas $(50 \mathrm{~mL}$ per $\mathrm{min}$ ) at $773 \mathrm{~K}$ for $2 \mathrm{~h}$ (hydrogen consumption was denoted as $A_{2}$ ). The dispersion $(D)$ of copper was calculated by $D=\left(2 A_{2} / A_{1}\right)^{*} 100 \%$.

Catalytic performance tests. The catalytic performance for DMO hydrogenation was evaluated by using a fixed-bed microreactor. Typically, $200 \mathrm{mg}$ of the catalyst was placed in the middle of the quartz tube and packed with quartz powders in the top side. The quartz tube was then loaded into the stainless steel tubular reactor. The catalyst was reduced under a $5 \% \mathrm{H}_{2}-95 \% \mathrm{~N}_{2}$ flow $(50 \mathrm{~mL}$ per min) at $573 \mathrm{~K}$ $\left(2{ }^{\circ} \mathrm{C}\right.$ per min) for $4 \mathrm{~h}$. The catalyst was cooled to desired reaction temperature ( $473 \mathrm{~K})$. Subsequently, $10 \mathrm{wt} \% \mathrm{DMO}$ in methanol and $\mathrm{H}_{2}$ were fed into the reactor at a $\mathrm{H}_{2} / \mathrm{DMO}$ molar ratio of 80 under a system pressure of $3.0 \mathrm{MPa}$. The liquid hourly space velocity of DMO was varied by changing the amount of feedstock. The outlet stream was sampled by an automatic Valco 6-ports valve system and analyzed by an online gas chromatograph (GC-9790, FuLi) with a flame ionization detector and a KB-Wax capillary column $(30 \mathrm{~m} \times 0.45 \mathrm{~mm} \times 0.85 \mu \mathrm{m})$ at intervals of $0.5 \mathrm{~h}$.

Computational details. DFT calculations are carried out by using the Vienna ab initio simulation package (VASP) ${ }^{51,52}$. Exchange and correlation were treated within the Perdew-Burke-Ernzerhof (PBE) generalized gradient approximation $(\mathrm{GGA})^{43}$.The valence electrons are described by plane wave basis sets with a cut off energy of $400 \mathrm{eV}$, and the core electrons are replaced by the projector augmented wave pseudopotentials ${ }^{53,54}$. For a clean $\mathrm{Cu}(111)$ surface, a $(5 \times 3)$ supercell with five layer slabs was used, which for the $\mathrm{SiO}_{2} / \mathrm{Cu}(111)$, the $\mathrm{Cu}(111)$ substrate was extended into the $(8 \times 4)$ structure. During structural optimization, the bottom two layer slabs were fixed at a bulk truncated position, while the surface layers and the adsorbates were fully relaxed. For all of the calculations, the vacuum regions between the slabs were more than $10 \AA$, and Monkhurst-Pack k-point sampling with approximately $0.05 \times 2 \pi \AA^{-1}$ spacing in a reciprocal lattice was utilized. The minimum energy reaction pathways were calculated using the nudged elastic band method. The final transition state structures were refined using a quasi-Newton algorithm until the Hellman-Feynman forces on each ion were lower than $0.03 \mathrm{eV}$ $\AA^{-1}$. The adsorption energies $\left(\Delta E_{\text {ads }}\right)$ were calculated using Eq. 1, in which $E_{\text {ad/surf }}$; $E_{\text {ad }}$, and $E_{\text {surf }}$ were the total energies of the optimized adsorbate/surface system, the adsorbate in the gas phase, and the surface respectively. For the DMO 
hydrogenation, we assumed that there already existed four adsorbed $\mathrm{H}$ atoms on the $\mathrm{Cu}(111)$ surface and $\mathrm{SiO}_{2} / \mathrm{Cu}(111)$ interface.

$$
\Delta E_{\text {ads }}=E_{\text {ad/surf }}-E_{\text {ad }}-E_{\text {surf }}
$$

Data availability. The data that support the findings of this study are available from the corresponding author upon reasonable request.

Received: 10 December 2017 Accepted: 18 July 2018

Published online: 22 August 2018

\section{References}

1. $\mathrm{Fu}, \mathrm{Q}$. et al. Interface-confined ferrous centers for catalytic oxidation. Science 875, 26-29 (2010).

2. Qiao, B. et al. Single-atom catalysis of $\mathrm{CO}$ oxidation using $\mathrm{Pt}_{1} / \mathrm{FeO}_{\mathrm{x}}$. Nat. Chem. 3, 634-641 (2011).

3. Chen, G. X. et al. Interfacial effects in iron-nickel hydroxide-platinum nanoparticles enhance catalytic oxidation. Science 344, 495-499 (2014)

4. Fu, Q., Yang, F. \& Bao, X. H. Interface-confined oxide nanostructures for catalytic oxidation reactions. Acc. Chem. Res. 46, 1692-1701 (2013).

5. Park, J. B. et al. High catalytic activity of $\mathrm{Au} / \mathrm{CeO}_{\mathrm{x}} / \mathrm{TiO}_{2}(110)$ controlled by the nature of the mixed-metal oxide at the nanometer level. Proc. Natl Acad. Sci. 106, 4975-4980 (2009).

6. Rodriguez, J. A. et al. Activity of $\mathrm{CeO}_{\mathrm{x}}$ and $\mathrm{TiO}_{\mathrm{x}}$ nanoparticles grown on $\mathrm{Au}$ (111) in the water-gas shift reaction. Science 318, 1757-1760 (2007).

7. Fu, Q., Saltsburg, H. \& Flytzani-Stephanopoulos, M. Active nonmetallic $\mathrm{Au}$ and Pt species on ceria-based water-gas shift catalysts. Science 301, 935-938 (2003).

8. Subbaraman, R. et al. Trends in activity for the water electrolyzer reactions on 3d M(Ni,Co,Fe,Mn) hydro(oxy)oxide catalysts. Nat. Mater. 11, 550-557 (2012).

9. Subbaraman, R. et al. Enhancing hydrogen evolution activity in water splitting by tailoring $\mathrm{Li}^{+}-\mathrm{Ni}(\mathrm{OH})_{2}-\mathrm{Pt}$ interfaces. Science 334, 1256-1260 (2011).

10. Danilovic, N. et al. Enhancing the alkaline hydrogen evolution reaction activity through the bifunctionality of $\mathrm{Ni}(\mathrm{OH})_{2} /$ metal catalysts. Angew. Chem. Int. Ed. 124, 12663-12666 (2012).

11. Strmcnik, D. et al. Improving the hydrogen oxidation reaction rate by promotion of hydroxyl adsorption. Nat. Chem. 5, 300-306 (2013).

12. Tauster, S. J., Fung, S. C. \& Garten, R. L. Strong interactions in supportedmetal catalysts. Science 211, 1121-1125 (1981).

13. Tauster, S. J. Strong metal-support interactions. Acc. Chem. Res. 20, 389-394 (1987).

14. Tauster, S. J. et al. Strong metal-support interactions. Group 8 noble metals supported on titanium dioxide. J. Am. Chem. Soc. 100, 170-175 (1978).

15. Matsubu, J. C. et al. Adsorbate-mediated strong metal-support interactions in oxide-supported Rh catalysts. Nat. Chem. 9, 120-127 (2017).

16. Rodriguez, J. A. et al. Ceria-based model catalysts: fundamental studies on the importance of the metal-ceria interface in CO oxidation, the water-gas shift, $\mathrm{CO}_{2}$ hydrogenation, and methane and alcohol reforming. Chem. Soc. Rev. 46, 1824-1841 (2017).

17. Graciani, J. et al. Highly active copper-ceria and copper-ceria-titania catalysts for methanol synthesis from $\mathrm{CO}_{2}$. Science 345, 546-550 (2014).

18. Zhang, Q. et al. Core-shell nanostructured catalysts. Acc. Chem. Res. 46, 1816-1824 (2013).

19. Zaera, F. Nanostructured materials for applications in heterogeneous catalysis. Chem. Soc. Rev. 42, 2746-2762 (2013).

20. Joo, S. H. et al. Thermally stable Pt/mesoporous silica core-shell nanocatalysts for high-temperature reactions. Nat. Mater. 8, 126-131 (2009).

21. Dai, Y. Q. et al. A sinter-resistant catalytic system based on platinum nanoparticles supported on $\mathrm{TiO}_{2}$ nanofibers and covered by porous silica. Angew. Chem. Int. Ed. 49, 8165-8168 (2010).

22. Hansen, T. W. et al. Sintering of catalytic nanoparticles: particle migration or Ostwald ripening? Acc. Chem. Res. 46, 1720-1730 (2013).

23. Wu, S. H., Mou, C. Y. \& Lin, H. P. Synthesis of mesoporous silica nanoparticles. Chem. Soc. Rev. 42, 3862-3875 (2013).

24. Gawande, M. B. et al. Core-shell nanoparticles: synthesis and applications in catalysis and electrocatalysis. Chem. Soc. Rev. 44, 7540-7590 (2015).

25. Yamada, Y. et al. Nanocrystal bilayer for tandem catalysis. Nat. Chem. 3, 372-376 (2011).

26. Berne, B. J. et al. Nitriles at silica interfaces resemble supported lipid bilayers. Acc. Chem. Res. 49, 1605-1613 (2016).
27. Yue, H. R. et al. A copper-phyllosilicate core-sheath nanoreactor for carbonoxygen hydrogenolysis reactions. Nat. Commun. 4, 2339 (2013).

28. Gong, J. L. et al. Synthesis of ethanol via syngas on $\mathrm{Cu} / \mathrm{SiO}_{2}$ catalysts with balanced $\mathrm{Cu}^{0}-\mathrm{Cu}^{+}$sites. J. Am. Chem. Soc. 134, 13922-13925 (2012).

29. Yue, H. R. et al. Ethylene glycol: properties, synthesis, and applications. Chem Soc. Rev. 41, 4218-4244 (2012).

30. Löffler, D. et al. Growth and structure of crystalline silica sheet on Ru (0001). Phys. Rev. Lett. 105, 146104 (2010).

31. Chen, M. S., Santra, A. K. \& Goodman, D. W. Structure of thin $\mathrm{SiO}_{2}$ films grown on Mo (112). Phy. Rev. B 69, 155404 (2004).

32. Shaikhutdinov, S. \& Freund, H. J. Ultrathin silica films on metals: the long and winding road to understanding the atomic structure. Acc. Chem. Res. 25, 49-67 (2013).

33. Konda, S. S. M. et al. Computational insights into the role of metal and acid sites in bifunctional metal/zeolite catalysts: a case study of acetone hydrogenation to 2-propanol and subsequent dehydration to propene. ACS Catal. 6, 123-133 (2015).

34. Sinha, N. K. \& Neurock, M. A first principles analysis of the hydrogenation of $\mathrm{C}_{1}-\mathrm{C}_{4}$ aldehydes and ketones over $\mathrm{Ru}(0001)$. J. Catal. 295, 31-44 (2012).

35. Toupance, T., Kermarec, M. \& Louis, C. Metal particle size in silica-supported copper catalysts. Influence of the conditions of preparation and of thermal pretreatments. J. Phys. Chem. B 104, 965-972 (2000).

36. Wang, Y. Q., et al. One-pot synthesis of nanotube-based hierarchical copper silicate hollow spheres. Chem. Commun. 0, 6555-6557 (2008).

37. Wang, X. et al. Thermally stable silicate nanotubes. Angew. Chem. Int. Ed. 43, 2017-2020 (2004).

38. Chen, $\mathrm{L}$. F. et al. $\mathrm{Cu} / \mathrm{SiO}_{2}$ catalysts prepared by the ammonia-evaporation method: texture, structure, and catalytic performance in hydrogenation of dimethyl oxalate to ethylene glycol. J. Catal. 257, 172-180 (2008).

39. Toupance, T. et al. Conditions of formation of copper phyllosilicates in silicasupported copper catalysts prepared by selective adsorption. J. Phys. Chem. B 106, 2277-2286 (2002)

40. Zhao, S. et al. Chemoselective synthesis of ethanol via hydrogenation of dimethyl oxalate on $\mathrm{Cu} / \mathrm{SiO}_{2}$ : Enhanced stability with boron dopant. J. Catal. 297, 142-150 (2013).

41. Wang, Z. Q. et al. High-performance and long-lived $\mathrm{Cu} / \mathrm{SiO}_{2}$ nanocatalyst for $\mathrm{CO}_{2}$ hydrogenation. ACS Catal. 5, 4255-4259 (2015).

42. Ye, R. P. et al. A new low-cost and effective method for enhancing the catalytic performance of $\mathrm{Cu}-\mathrm{SiO}_{2}$ catalysts for the synthesis of ethylene glycol via the vapor-phase hydrogenation of dimethyl oxalate by coating the catalysts with dextrin. J. Catal. 350, 122-132 (2017).

43. Yue, H. R., Ma, X. B. \& Gong, J. L. An alternative synthetic approach for efficient catalytic conversion of syngas to ethanol. Acc. Chem. Res. 47, 1483-1492 (2014)

44. He, Z. et al. Effect of boric oxide doping on the stability and activity of a Cu$\mathrm{SiO}_{2}$ catalyst for vapor-phase hydrogenation of dimethyl oxalate to ethylene glycol. J. Catal. 277, 54-63 (2011).

45. Huang, Y. et al. Silver-modulated $\mathrm{SiO}_{2}$-supported copper catalysts for selective hydrogenation of dimethyl oxalate to ethylene glycol. J. Catal. 307, 74-83 (2013).

46. Yin, A. Y. et al. The nature of active copper species in Cu-HMS catalyst for hydrogenation of dimethyl oxalate to ethylene glycol: new insights on the synergetic effect between $\mathrm{Cu}$ and $\mathrm{Cu}^{+}$. J. Phys. Chem. C 113, 11003-11013 (2009).

47. Chusuei, C. C., Brookshier, M. A. \& Goodman, D. W. Correlation of relative $\mathrm{X}$-ray photoelectron spectroscopy shake-up intensity with $\mathrm{CuO}$ particle size. Langmuir 15, 2806-2808 (1999).

48. Fang, W. J. et al. Photo- and pH-triggered release of anticancer drugs from mesoporous silica-coated Pd@Ag nanoparticles. Adv. Funct. Mater. 22, 842-848 (2012)

49. Xiong, S. L. \& Zeng, H. C. Serial ionic exchange for the synthesis of multishelled copper sulfide hollow spheres. Angew. Chem. Int. Ed. 51, 949-952 (2012).

50. Fang, W. J. et al. Pd nanosheet-covered hollow mesoporous silica nanoparticles as a platform for the chemo-photothermal treatment of cancer cells. Small 8, 3816-3822 (2012).

51. Kresse, G. \& Furthmüller, J. Efficient iterative schemes for ab initio totalenergy calculations using a plane-wave basis set. Phy. Rev. B 54, 11169-11186 (1996).

52. Kresse, G. \& Furthmüller, J. Efficiency of ab initio total energy calculations for metals and semiconductors using a plane-wave basis set. Comput. Mater. Sci. 6, 15-50 (1996).

53. Blöchl, P. E. Projector augmented-wave method. Phy. Rev. B 50, 17953-17979 (1994).

54. Kresse, G. \& Joubert, D. From ultrasoft pseudopotentials to the projector augmented-wave method. Phys. Rev. B 59, 1758-1775 (1999). 


\section{Acknowledgements}

We thank the National Key R\&D Program of China (2017YFA0207302,

2017YFA0207303, 2017YFA0206801), the NNSF of China (21731005, 21420102001,

21721001, 21333008, 21373167, 21573178), and the Fundamental Research Funds for the Central Universities (20720160046) for financial support.

\section{Author contributions}

C. X. and G. C. conceived and carried out experiments, analyzed data, and wrote the paper. C. X. and G. C. contributed equally to this work. N. Z. designed the study, supervised the project, analyzed data, and wrote the paper. P. L., Y. Z. and G. F. carried out the density functional calculations, analyzed result and wrote the paper. L. G. carried out the STEM measurements. X. D. and Y. Y. carried out catalytic tests. All the authors contributed to the paper revision.

\section{Additional information}

Supplementary Information accompanies this paper at https://doi.org/10.1038/s41467018-05757-6.

Competing interests: The authors declare no competing interests.

Reprints and permission information is available online at http://npg.nature.com/ reprintsandpermissions/
Publisher's note: Springer Nature remains neutral with regard to jurisdictional claims in published maps and institutional affiliations.

(C) Open Access This article is licensed under a Creative Commons Attribution 4.0 International License, which permits use, sharing, adaptation, distribution and reproduction in any medium or format, as long as you give appropriate credit to the original author(s) and the source, provide a link to the Creative Commons license, and indicate if changes were made. The images or other third party material in this article are included in the article's Creative Commons license, unless indicated otherwise in a credit line to the material. If material is not included in the article's Creative Commons license and your intended use is not permitted by statutory regulation or exceeds the permitted use, you will need to obtain permission directly from the copyright holder. To view a copy of this license, visit http://creativecommons.org/ licenses/by/4.0/.

(c) The Author(s) 2018 